\title{
MANUFACTURE OF COAXIAL COPPER-ALUMINIUM RODS USING EXPLOSION WELDING AND DRAWING
}

\author{
A.G. BRYZGALIN ${ }^{1}$, L.D. DOBRUSHIN ${ }^{1}$, P.S. SHLENSKY ${ }^{1}$, I.G. LAVRENKO ${ }^{2}$ and I.M. ROMASHKO ${ }^{2}$ \\ ${ }^{1}$ E.O. Paton Electric Welding Institute, NASU \\ 11 Bozhenko Str., 03680, Kiev, Ukraine. E-mail: office@paton.kiev.ua \\ ${ }^{2} \mathrm{SE}$ «Antonov» \\ 1 Tupolev Str., 03082, Kiev, Ukraine. E-mail: info@antonov.com
}

\begin{abstract}
Replacement of copper during production of current-conducting busbars by aluminium clad with a thin layer of copper allows reducing metal intensity of products preserving the high electric conductivity. The technology of manufacture of coaxial copper-aluminium current-conducting rods using explosion welding and drawing was offered. The modes of heat treatment of rods after drawing were experimentally selected providing the required mechanical properties at a minimum number of forming intermetallics. The methods of calculation of sizes of initial billets providing obtaining the required geometric parameters of a product were described. The possibility of application of explosion reduction of billets instead of explosion welding is shown. 5 Ref., 2 Tables, 7 Figures.
\end{abstract}

$\boldsymbol{K} \boldsymbol{e} \boldsymbol{y} \boldsymbol{w} \boldsymbol{o} \boldsymbol{r} \boldsymbol{d} \boldsymbol{s}:$ copper-aluminium rods, electric conductivity, explosion welding, drawing, bimetal

The current-conducting busbars of electric equipment of critical purpose are produced of copper, having a high electric conductivity and, at the same time, a high density [1]. The replacement of solid copper busbars by aluminium ones with the thin copper layer provides a considerable decrease of mass of products preserving their electric conductivity. However, the existing technologies, which would allow producing bimetal billets admitting the further rolling and bending at big angles without violations of mechanical integrity and reliable electric contact, suppose using of the rather expensive import equipment.

To produce $\mathrm{Cu}-\mathrm{Al}$ bimetal in Ukraine and abroad the explosion welding is widely applied. This material finds application in power-consuming fields of industry as current-conducting and transition elements due to the transition resistance of a joint close to zero. In spite of the fact that both materials are characterized by high ductile properties, which is necessary to produce quality welded joint, the providing of full strength and zero defects in explosion welding is problematic by a number of reasons connected with considerable differences in physical and mechanical properties of metals and also rather unfavorable type of metallurgy interaction from the position of weldability with formation of a number of intermetallics of the $\mathrm{Al}_{2} \mathrm{Cu}, \mathrm{AlCu}, \mathrm{AlCu}_{2}$, $\mathrm{Al}_{2} \mathrm{Cu}_{3}$ type [2].

At the E.O. Paton Electric Welding Institute the technology of manufacture of bimetal $\mathrm{Cu}-\mathrm{Al}$ rods using explosion joining of copper shell with aluminium rod and further drawing was developed. According to the technical assignment (TA) it was necessary to manufacture the bimetal rods of 8 and $9 \mathrm{~mm}$ diameter with thickness of copper coating of not less than $0.3 \mathrm{~mm}$ and required level of mechanical properties: ultimate tensile strength of rod of not less than $90 \mathrm{MPa}$ and elongation of not less than $25 \%$.

Bimetal billet was manufactured by weldingon of copper tube with outer diameter of $28 \mathrm{~mm}$ and wall thickness of $1 \mathrm{~mm}$ to aluminium rod of $24 \mathrm{~mm}$ diameter. The given geometric parameters were selected basing on assumption about conservation of mass and volume of applied materials during drawing, conditions of providing the required finite sizes of rod and optimum modes of explosion welding. Aluminium rod 2 (Figure 1) was grinded to render it the shape, setting a welding gap and shaping of stem for the further

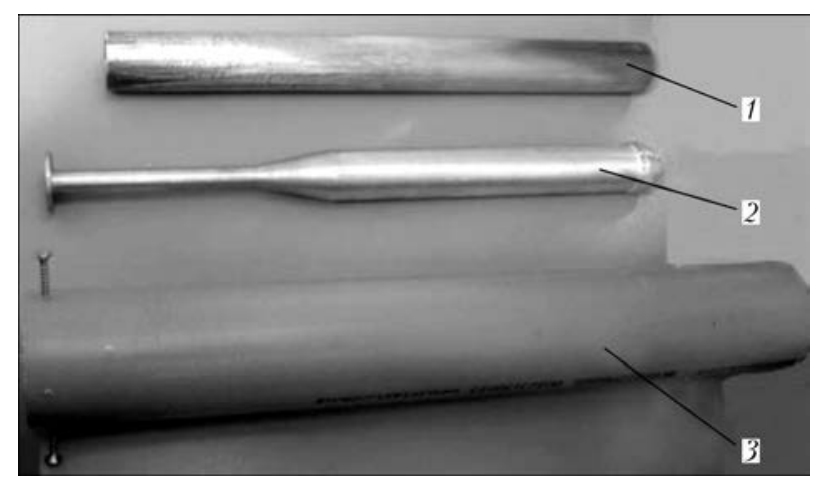

Figure 1. Basic composing elements for explosion welding of bimetal rod: 1 - copper tube; 2 - aluminium rod; 3 polyethylene pipe serving as a container for explosive 
Figure 2. Billet for drawing of bimetallic rod produced using explosion welding

drawing. The assembly for explosion welding was performed by positioning of aluminium rod inside the copper tube 1 with welding gap of $1 \mathrm{~mm}$. The copper tube in its turn was maximum inserted to the polyethylene pipe with inner diameter of $47 \mathrm{~mm}$, which served as a container for explosive 3.

The thickness of charge, representing a mixture of ammonite $6 \mathrm{ZhV}$ with ammonia niter, amounted to $9.5 \mathrm{~mm}$. The selected mode of welding provided producing of quality billets for the further drawing (Figure 2).

The joint boundary did not have a wave formation, characteristic of explosion welding, which evidences of performing welding at the lower limit of admissible modes, i.e. with minimum energy input [3]. It allowed minimizing the number of intermetallics formed in welding (about $10 \%$ along the length of the joint) ( $\mathrm{Fi}-$ gure $3, a)$.

The drawing of bimetal rods was performed in the equipment of the PWI Research Center «Explosion Treatment of Materials». It was found that optimum decrease of diameter of bimetal billet per one pass amounts to $0.5 \mathrm{~mm}$. Here it is not required to conduct heat treatment of billets at all the stages of drawing operation.

The investigation of mechanical properties of bimetal rods after drawing showed that they met the requirements specified by the customer. In this connection the rods were subjected to heat treatment at the modes given in Table 1. Figure 3 shows photos of microstructure of the joint in initial as-welded and as-drawn condition and after heat treatment at some of the mentioned modes. In the initial state the intermetallics are almost absent, after heat treatment at mode 2 (see Table 1) the intermetallics appeared, heat
Table 1. Mechanical properties of bimetal rods produced using explosion welding and drawing

\begin{tabular}{|c|c|c|c|c|}
\hline $\begin{array}{l}\text { Number } \\
\text { of mode }\end{array}$ & State of specimen & $\sigma_{\mathrm{y}}, \mathrm{MPa}$ & $\sigma_{\mathrm{t}}, \mathrm{MPa}$ & $\delta, \%$ \\
\hline 1 & Initial & 121 & 150 & 12 \\
\hline 2 & HT at $180{ }^{\circ} \mathrm{C}$ for $30 \mathrm{~min}$ & 143 & 150 & 13 \\
\hline 3 & HT at $250{ }^{\circ} \mathrm{C}$ for $60 \mathrm{~min}$ & 171 & 187 & 18 \\
\hline 4 & HT at $300{ }^{\circ} \mathrm{C}$ for $40 \mathrm{~min}$ & 127 & 149 & 28 \\
\hline 5 & $\mathrm{HT}$ at $350{ }^{\circ} \mathrm{C}$ for $60 \mathrm{~min}$ & 44 & 113 & 57 \\
\hline 6 & $\begin{array}{c}\text { «Copperweld» } \\
\text { bimetal rod (USA) }\end{array}$ & 186 & - & 11 \\
\hline
\end{tabular}

treatment at mode 5 resulted in increase of their number and sizes.

Mechanical properties of bimetal rods of $9 \mathrm{~mm}$ diameter, produced using explosion welding and drawing, and also bimetal rods, produced in the Copperweld installation (USA) of $8 \mathrm{~mm}$ diameter, and TA requirements are also given in $\mathrm{Ta}^{-}$ ble 1 .

The bimetal rods subjected to heat treatment at $300{ }^{\circ} \mathrm{C}$ for $40 \mathrm{~min}$, meet also TA requirements. Such products revealed a sufficiently high ability to deformation both at standard tests for bending (Figure 4) [4, 5], as well as at formation of contact areas of current-conducting busbars.

At the bending tests the rods without heat treatment withstood three bends at $180^{\circ}$ and had a fracture with separation of copper layer from aluminium base, the rods which passed heat treatment at mode 4 withstood 24 bends, and fracture had no delaminations.

The measurement of specific electric resistance $R$ of annealed bimetal rod (mode 4) to direct current in recalculation for temperature of $20{ }^{\circ} \mathrm{C}$, amounted to $0.027 \cdot 10^{-6} \mathrm{Ohm} \cdot \mathrm{m}$, which corresponds to TA requirements.

Achievement of the quality explosion welding of billets requires thorough keeping of welding parameters, that predetermines a high labor in-
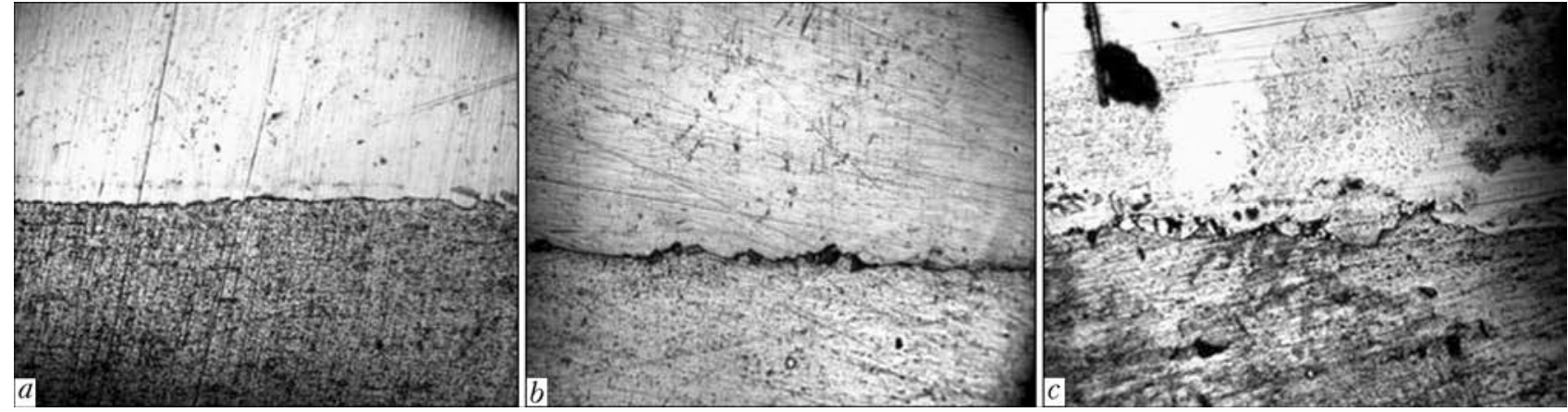

Figure 3. Microstructure $(\times 200)$ of $\mathrm{Cu}-\mathrm{Al}$ joint: $a-$ in initial state after welding and drawing; $b-$ after heat treatment at $180{ }^{\circ} \mathrm{C}$ for $30 \mathrm{~min} ; c$ - after heat treatment at $350{ }^{\circ} \mathrm{C}$ for $60 \mathrm{~min}$ 

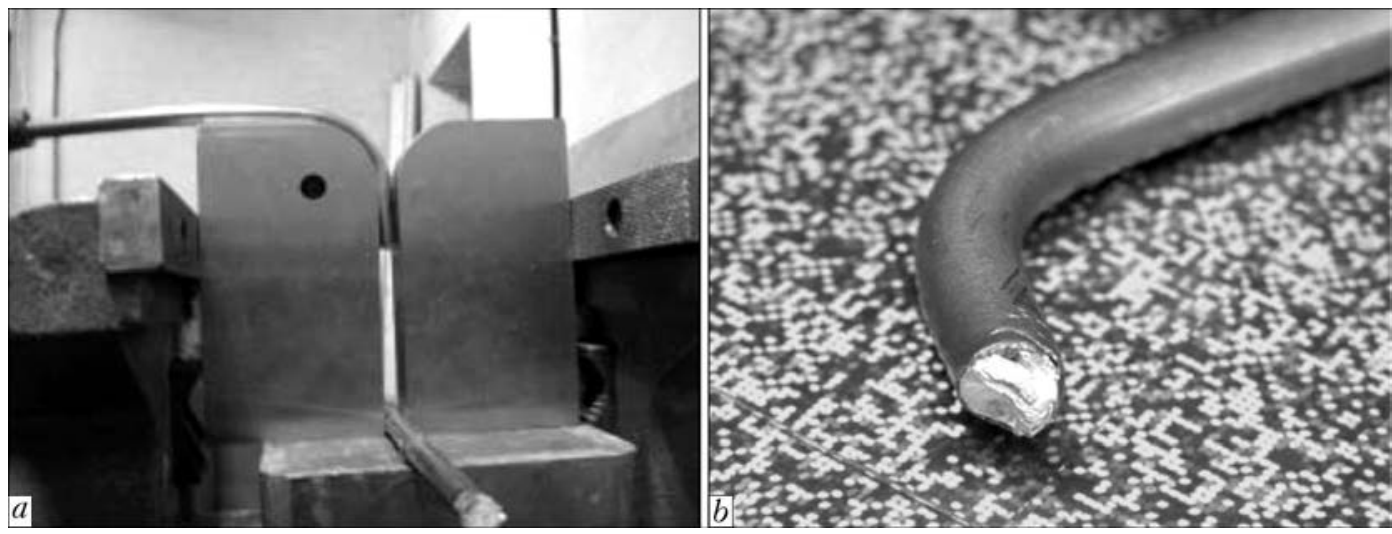

Figure 4. General view of bend test $(a)$, and appearance of rod fracture $(b)$

tensity of preparation operations. In this connection the peculiar interest is represented by a possibility of production of coaxial rods according to the explosion reduction + drawing scheme.

The joining of bimetal billet using reduction without forced formation of welded joint has a number of advantages:

- less severe requirements to the modes of explosion treatment as compared to explosion welding and, respectively, increase in efficiency and decrease in cost effectiveness;

- decrease in mass of the applied explosive charge;

- possibility of using explosives with any detonation rate.

Here, the explosion reduction provides cumulative cleaning of the surfaces being joined, that gives grounds to expect a possibility of diffusion welding, the process of which is accelerated during drawing and heat treatment of billets.

To manufacture coaxial bimetal rods according to the reduction + drawing scheme, the following billets were used:

- aluminium rod of AD1 grade of $15 \mathrm{~mm}$ diameter and $300 \mathrm{~mm}$ length;

- copper tube (M2) with outer diameter of $20 \mathrm{~mm}, 1 \mathrm{~mm}$ wall thickness and $300 \mathrm{~mm}$ length.

After explosion reduction the bimetal billet with variable diameter of $17.5-18.0 \mathrm{~mm}$ was produced. The difference in diameter along the billet length is explained by presence of air gaps between the layer of copper and aluminium rod. The volume of bubbles relatively to the volume of primary billets amounted to $10 \%$ (the volume of bubbles was calculated as a difference of volume of initial billets and bimetal billet after explosion reduction).

The bimetal rod was produced using drawing with a pitch of decrease of $0.5 \mathrm{~mm}$ diameter without intermediate heat treatment. The length of produced rod considering the technological losses on manufacture of stems for clamping of billet during drawing amounted to $930 \mathrm{~mm}$. The length of rod with quality coating after removal of beginning and end of the rod with a rejected coating amounted to $845 \mathrm{~mm}$, the visual inspection showed the absence of air bubbles and surface defects. The diameter of rod produced after drawing amounted to $8.91-8.94 \mathrm{~mm}$, the average value (according to 10 measurements) was $8.92 \mathrm{~mm}$. The thickness of copper layer was $0.535-0.6 \mathrm{~mm}$, the average value $-0.587 \mathrm{~mm}$.

Mechanical properties of bimetal specimens were determined directly after drawing and also after reduction according to mode $1\left(180{ }^{\circ} \mathrm{C}\right.$ for $0.5 \mathrm{~h})$ and mode $2\left(350{ }^{\circ} \mathrm{C}, 1 \mathrm{~h}\right)$. The data of tensile tests are given in Table 2 .

The examination of microstructure was carried out on sections in the initial state and after heat treatment at modes 1 and 2 (Figure 5).

For evaluation of influence of heat treatment on state of intermetallics the area of section in the initial state after reduction and drawing was selected (Figure 5, $a$ ). The same area of section with characteristic intermetallic inclusions is presented in Figure 5, $b$ and $c$ after heat treatment in the beginning at mode 1 and then at mode 2 . Mode 1 did not result in formation of intermetallic interlayer and growth of the existing intermetallics. During tempering at mode 2 the intermetallic interlayer of about $10 \mu \mathrm{m}$ thickness was formed.

The line of $\mathrm{Cu}-\mathrm{Al}$ joint has no delaminations and other defects of discontinuities. The areas with characteristic wave formation deformed after drawing are observed. On some waveless areas

Table 2. Mechanical properties of bimetal rods produced using explosion welding and drawing

\begin{tabular}{|c|c|c|c|c||}
\hline $\begin{array}{c}\text { Number } \\
\text { of mode }\end{array}$ & Type of specimen & $\sigma_{\mathrm{y}}, \mathrm{MPa}$ & $\sigma_{\mathrm{t}}, \mathrm{MPa}$ & $\delta, \%$ \\
\hline 1 & Initial & 144 & 150 & 12 \\
\hline 2 & $\mathrm{HT}$ at $180^{\circ} \mathrm{C}$ for $30 \mathrm{~min}$ & 143 & 150 & 13 \\
\hline 3 & $\mathrm{HT}$ at $350^{\circ} \mathrm{C}$ for $60 \mathrm{~min}$ & 44 & 113 & 57 \\
\hline
\end{tabular}




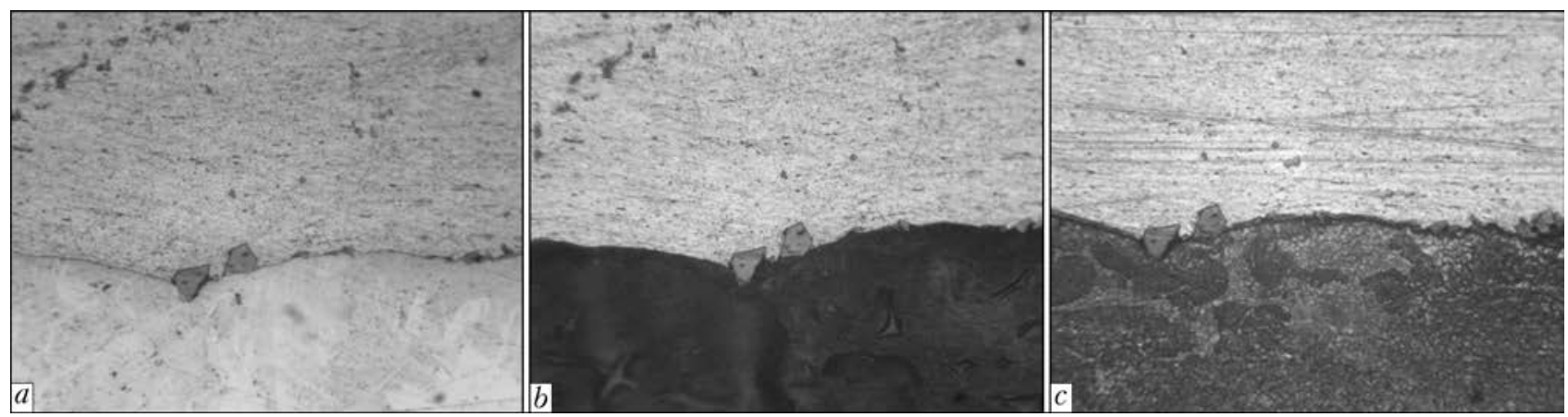

Figure 5. Microstructure $(\times 200)$ of joint: $a$ - in initial state after reduction and drawing; $b$ - after heat treatment at $180{ }^{\circ} \mathrm{C}$ for $30 \mathrm{~min} ; \mathrm{c}-$ after heat treatment at $350{ }^{\circ} \mathrm{C}$ for $60 \mathrm{~min}$

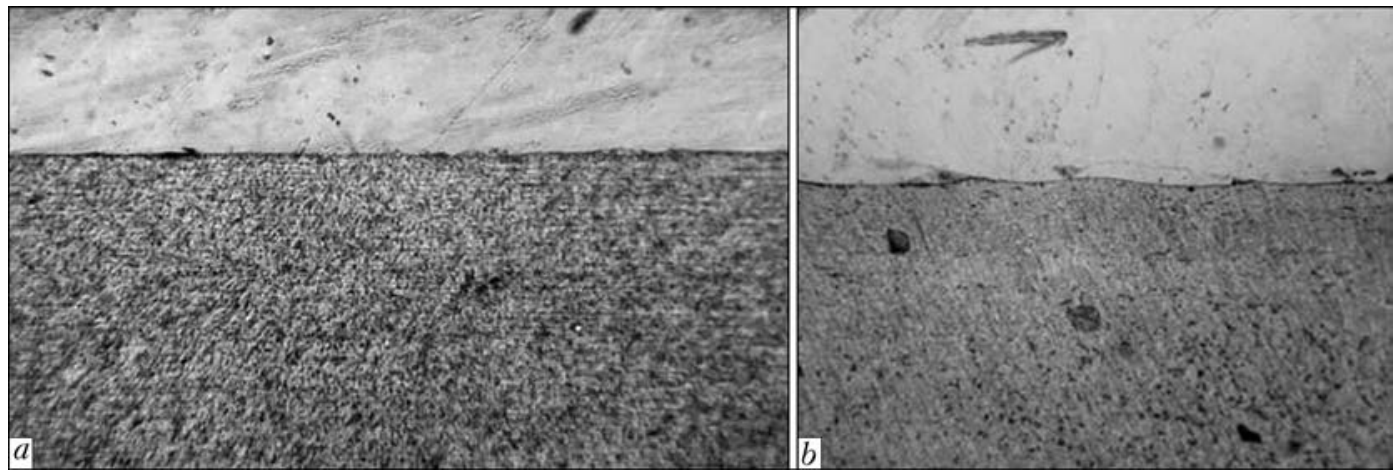

Figure 6. Microstructure $(\times 200)$ of a $\mathrm{Cu}-\mathrm{Al}$ joint after explosion reduction and drawing: $a-$ waveless joint; $b-$ introduction of aluminium particles to the copper base

along the line of joining in the zone of welding the chains of aluminium inclusions into the copper base are noted. Most obviously, in these spots the waves from explosion welding were broken during drawing, that resulted in introduction of aluminium particles to the copper base ( $\mathrm{Fi}^{-}$ gure 6).

The formation of intermetallics in the form of a chain of grains along the joining line was also revealed in some areas. The total length of areas with intermetallics amounts to about $20-25 \%$. Providing the required mechanical and electric parameters of the rod needs selection of optimal modes of explosion reduction (in the given case

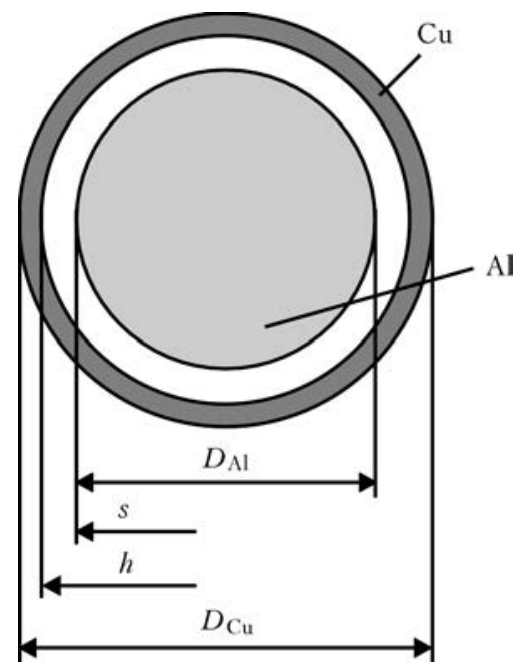

Figure 7. Parameters of coaxial billet for explosion welding decrease in the charge energy and decrease in the gap) and heat treatment.

For selection of optimum type and size of the initial billets of aluminium rod and copper tube (Figure 7) the method of calculation evaluation of their geometry parameters was proposed. Here it is supposed that welding gap between copper and aluminium is equal to thickness of wall of copper tube (that corresponds to the practical modes of welding) and calculation values of the second order of smallness are neglected.

The customer preset the diameter of $\operatorname{rod} d$, which should be manufactured and the admissible thickness of copper layer $h_{\mathrm{i}}$ in it. During manufacture of billets they are oriented to the purchased copper tube with the standard type and size determined by its outer diameter $D_{\mathrm{Cu}}$ and thickness of wall $h$. To increase the efficiency, $D_{\mathrm{Cu}}$ should be as high as it can and limited by the capabilities of drawing equipment. Basing on these assumptions the standard diameter of the copper tube is selected and the calculation thickness of its wall is determined according to the expression

$$
h_{\mathrm{c}}=h_{\mathrm{i}} D_{\mathrm{Cu}} / d .
$$

The value $h$ is determined by the approximation $h_{\mathrm{c}}$ up to the highest standard one. The thickness of copper layer in the product is calculated by the expression 


$$
h_{\mathrm{i}}=h d / D_{\mathrm{Cu}}
$$

and will be deliberately higher than that determined by the customer. Varying the standard diameter of copper tube, one can select its most optimum type and size considering the requirements to the value $h_{\mathrm{i}}$ and efficiency of the process of manufacture of the rod.

The diameter of aluminium $\operatorname{rod} D_{\mathrm{Al}}$ is calculated in the following way:

$$
D_{\mathrm{Al}}=D_{\mathrm{Cu}}-2 h-2 s,
$$

where $s$ is the welding gap.

The coefficient of elongation is determined during drawing:

$$
K=\left(D_{\mathrm{Cu}}^{2}-4 D_{\mathrm{Al}} h\right) / d^{2} .
$$

The length of cylindrical part of billets $L_{\mathrm{b}}$ is determined basing on the minimum length of rod $L_{\mathrm{r}}$ preset by the customer:

$$
L_{\mathrm{b}} \geq L_{\mathrm{r}} / K+L_{\mathrm{st}},
$$

where $L_{\text {st }}$ is the length of billet considering the manufacture of intermediate stems and is determined by the drawing technology.

According to the results of $\mathrm{R} \& \mathrm{D}$ the batch of $\mathrm{Cu}-\mathrm{Al}$ rods of 8 and $9 \mathrm{~mm}$ diameter was manufactured allowing practicing the technology of manufacture of current-conducting busbars and carrying out their tests.

\section{Conclusions}

1. The technology of manufacture of $\mathrm{Cu}-\mathrm{Al}$ rods for electric engineering purposes using explosion welding and drawing providing their high ductile and electric conducting properties was developed.

2. The principal possibility of manufacture of a rod using explosion reduction and drawing was shown.

3. The technical specifications «Aluminiumcopper electrotechnical rod of the PAM grade» on manufacture and delivery of copper-aluminium rods of $8-10 \mathrm{~mm}$ diameter were worked out.

1. GOST 434-78: Wire of rectangular section and copper busbars for electric engineering purposes. Technical assignment

2. Kudinov, V.M., Koroteev, A.Ya. (1978) Explosion welding in metallurgy. Moscow: Metallurgiya.

3. Lysak, V.I., Kuzmin, S.V. (2005) Explosion welding. Moscow: Mashinostroenie.

4. GOST 1579-93: Wire. Overbending tests

5. GOST 7229-76: Cables, wires and cords. Method for determination of electric resistance of conductive cores and conductors.

Received 26.01.2015 